\title{
Políticas Públicas De Erradicação Do Trabalho Infantil: Uma Reflexão Apoiada No Projeto Algodão Com Trabalho Decente
}

\author{
Gerardo Clésio Maia Arruda*
}

Centro Universitário Christus e Universidade de Fortaleza, Programa de PósGraduação em Direito da UNICHRISTUS, Fortaleza, Ceará, Brasil.

ORCID http://orcid.org/0000-0002-116.5-8137

\section{Ticyanne Pereira da Silva **}

Centro Universitário Christus, Programa de Pós-Graduaçaõ em Direito, Fortaleza, Ceará, Brasil.

\section{http://orcid.org/oooo-0001-7243-2759}

Resumo: O projeto de Cooperação Algodão com Trabalho Decente objetiva contribuir para a erradicação do trabalho infantil, um fenômeno que está associado à pobreza extrema, à desigualdade social e à falta de educação. Concebido pela Organização Internacional do Trabalho (OIT), o projeto é executado em parceria com a Agência Brasileira de Cooperação (ABC) e com o Instituto Brasileiro do Algodão (IBA). Apesar do sucesso do projeto, as estatísticas acerca do trabalho infantil, no Brasil, ainda são elevadas, sendo a região Nordeste a que apresenta mais alta incidência. Objetiva-se, neste artigo, analisar as causas da inserção precoce de jovens no mercado de trabalho, no intuito de contribuir para o fortalecimento das ações estatais direcionadas para o combate ao trabalho da criança e do adolescente. A metodologia se fundamenta na abordagem histórico-estrutural e privilegia a pesquisa bibliográfica. Conclui-se que ações estatais, como a do projeto de Cooperação Algodão com Trabalho Decente, devem ser promovidas pelos agentes públicos, uma vez que o desenvolvimento é alcançado não só pelo investimento de capital, mas também pela análise das peculiaridades do local, com a promoção do diálogo entre os atores envolvidos ativamente e o investimento no capital humano.

Palavras-chave: Políticas Públicas. Desenvolvimento. Trabalho infantil.

\footnotetext{
* Centro Universitário Christus (UNICHRISTUS)Professor do Programa de Mestrado em Direito do Centro Universitário Christus (UNICHRISTUS) e Professor Titular da Universidade de Fortaleza (UNIFOR). Doutor e Mestre em Sociologia, Especialista em Geografia e Graduado em Ciências Econômicas.

E-mail: clesioarruda@yahoo.com.br

** Mestranda em Processo e Direito ao Desenvolvimento pela UNICHRISTUS.

E-mail: ticyps@hotmail.com
}

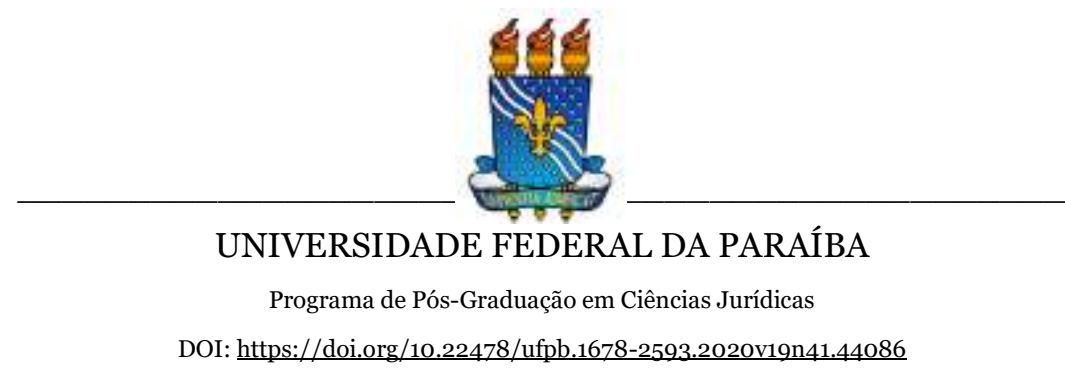




\title{
Políticas Públicas De Erradicação Do Trabalho Infantil: Uma Reflexão Apoiada No Projeto Algodão Com Trabalho Decente
}

\author{
Ticyanne Pereira da Silva
}

Gerardo Clésio Maia Arruda

\section{INTRODUÇÃO}

O presente artigo investiga o trabalho da criança e do adolescente, mais especificamente na região Nordeste, buscando, inicialmente, compreender as causas culturais que influenciam na construção da ideia que impulsiona o jovem para a inserção precoce no mercado de trabalho; também, averigua a produção legislativa direcionada para a regulação do trabalho infanto juvenil no país; e, principalmente, faz uma reflexão analítica do Projeto Algodão com Trabalho Decente, uma proposição da Organização Internacional do Trabalho (OIT), em parceria com a Agência Brasileira de Cooperação (ABC) e com o Instituto Brasileiro do Algodão (IBA). Espera-se contribuir com a discussão sobre o trabalho da criança, precipuamente no que concerne à elaboração de proposições normativas e de políticas públicas visando à coibição de sua prática.

O ensino fundamental evoluiu, significativamente, em relação ao número de alunos matriculados e à redução de abandono, de sorte que se encontra praticamente universalizado na sociedade brasileira. Entretanto, ao se examinar os dados referentes à passagem deste para o nível subsequente, observa-se que ocorre uma queda substancial de alunos matriculados, ou seja, em 2016, verificou-se que o total de 
matrículas nos anos iniciais atingiu, no ensino fundamental, o total de 15.346.0o8, enquanto no ensino médio somou 8.131.988, o que representa uma queda de matrículas da ordem de $47 \%$ (INEP, 2016).

Vê-se que é substancial o número de jovens que não dão continuidade aos estudos, fato este motivado principalmente pelo ingresso precoce no mercado de trabalho. Eis uma questão social que pode alcançar largas proporções nas próximas décadas, pois o mercado de trabalho, cada vez mais demandante de conhecimento, torna-se mais seletivo. Tal fenômeno ocorre porque, como asseveram Lazzarato e Negri (2001), é uma característica da economia contemporânea o aperfeiçoamento dos equipamentos, dos materiais e dos sistemas produtivos, enfim, a inovação tecnológica contínua.

Com efeito, a sociedade precisa de trabalhadores mais qualificados - no sentido da aptidão para a capacidade de aprendizado contínuo - e a entrada precoce numa atividade produtiva limita o desenvolvimento cognitivo do indivíduo, dado o seu afastamento do ensino no período de maior facilidade de introjeção de elementos essenciais ao aprendizado. Por isto, urge a necessidade do debate acerca do trabalho da criança e do adolescente a partir de várias áreas do conhecimento, pois, quanto mais a sociedade brasileira retardar o enfrentamento da evasão escolar dos jovens, maior será a intensificação dos problemas sociais como o desemprego e a violência.

O artigo 54 do Estatuto da Criança e do Adolescente (ECA) explicita a existência da obrigatoriedade e da gratuidade do ensino fundamental e médio; e imputa, no artigo 55, aos pais e aos responsáveis, o dever de matricular seus filhos na rede regular de ensino. Vê-se aí que não se está diante de matéria negligenciada em seu aspecto jurídico, pois existe uma normatização que torna obrigatória a educação dos jovens. Na verdade, o problema reside na necessidade da efetivação de tais normas; um empreendimento que demanda a formulação de um consenso social indutor da indignação coletiva quando da constatação da existência de jovens fora da escola, 
instituidor de opiniões públicas impositivas de mudanças reais, portanto, que seja capaz de criar uma vontade política irresistível.

A luta contra o trabalho do jovem tomou força no mundo todo, após a percepção das consequências negativas no desenvolvimento físico e psicológico de crianças e adolescentes. Entretanto, a atividade laboral encontra-se consagrada no imaginário popular como forma legítima de complementação de renda familiar e de estratégia para manter os jovens de baixa renda afastados da delinquência.

Portanto, faz-se mister a adoção de políticas públicas que sejam efetivas também na construção de uma mentalidade coletiva contrária à inserção precoce em atividades laborais, como o Projeto Algodão com Trabalho Decente, desenvolvido pela Organização Internacional do Trabalho (OIT), em parceria com a Agência Brasileira de Cooperação ( $\mathrm{ABC}$ ) e com o Instituto Brasileiro do Algodão (IBA).

Em suma, o trabalho infantil está hermeticamente vinculado ao tema da dignidade da pessoa humana, ou seja, a questão dos direitos humanos e, subsequentemente, dos direitos sociais; sendo, nessa perspectiva, de fundamental importância para o campo jurídico.

\section{SOBRE A ORIGEM DA LEGITIMAÇÃO SOCIAL DO TRABALHO INFANTIL NO NORDESTE}

A partir do estudo das relações sociais circunscritas a uma área geográfica específica, o semiárido do Nordeste, busca-se, nesse tópico, compreender como se estruturam alguns padrões comportamentais pertinentes à cultura rural, principalmente aqueles que privilegiam a ocupação dos jovens em atividades laborais impeditivas de um tempo mais prolongado na escola. Um fenômeno que se dá, essencialmente, sobre as crianças e os adolescentes pertencentes às classes sociais de baixa renda, pois as de renda média e alta priorizam a complementação da formação educacional através de atividades de conhecimentos linguísticos, culturais ou prática de esportes e, quando 
muito, admitem a ocupação em trabalhos não comprometedores do estudo formal obrigatório.

$\mathrm{Na}$ zona rural do semiárido, até meados do século $\mathrm{XX}$, as famílias produziam quase tudo o que era necessário à sua existência. Arruda (2003) explica que decorre, desse modo, a formação de uma sociedade no campo com uma baixa relação de dependência entre as pessoas, tornando-as isoladas e individualizadas na luta para satisfazer as suas necessidades, concorrendo para a existência de similitude e não de complementaridade das ações cotidianas de cada um.

Essa característica é comum à grande parte das comunidades rurais e proporciona um tipo de vida em que as pessoas compartilham um cotidiano semelhante, na medida em que a atividade que o indivíduo realiza se repete diuturnamente sem grandes variações e não há diferenças significativas do modo como os seus vizinhos também as realizam. Nessas condições, o conhecimento de uns em relação aos outros possui um sentido pleno, conhece-se amplamente a personalidade do próximo, de sorte que não se trata de algo parcial e limitado, condicionado a uma atividade específica, como ocorre nas cidades. Esclarece Mendras (1978, p. 88), que, ao contrário do que se passa nas zonas urbanas; no cotidiano rural, tem-se "um conhecimento total e prolongado da pessoa do outro, no conjunto de suas posições sociais atuais e passadas, e nas particularidades de sua personalidade.

Na verdade, como descreve Arruda (2003), os sertanejos, no período que antecede à industrialização e ao alargamento do comércio que originou as cidades de médio porte, relacionavam-se mais frequentemente com os membros de suas famílias e só em raras ocasiões - quando dos mutirões e das festividades - com os vizinhos. Resulta daí que o modo de agir, pensar e sentir era influenciado por pessoas com um tipo de vida próximo, na medida em que trabalhavam com os irmãos, sob as ordens do pai; conversavam com as mães, nos intervalos entre o trabalho e as brincadeiras; brincavam com crianças 
inseridas no mesmo cotidiano.

Mas há que se considerar ainda o aspecto de que o sertão, até a primeira metade do século XX era também um mundo que atribuía pouca importância à escrita, à leitura. Era um mundo de poucas palavras e letras. Os sertanejos estavam inseridos num universo cultural que não era capaz de dotá-los de uma expectativa favorável em relação à instrução formal, porque não viam como objetivar na sua vida cotidiana o conhecimento. Portanto, não é estranho que o camponês hierarquize os valores que o distinguem positivamente, como afirma Queiroz (1973, p. 55), na seguinte ordem: “desinteresse, generosidade, respeito pelos outros, bondade, coragem, bom-senso e, em último lugar, instrução."

Nas ponderações do personagem Fabiano, da obra de Graciliano Ramos, Vidas Secas, é possível vislumbrar o tipo de conhecimento valorizado pelos que vivem no sertão: “Indispensável os meninos entrarem no bom caminho, saberem cortar mandacaru para o gado, consertar cercas, amansar brabos.” (RAMOS, 1988, p.24). Fabiano acredita que se deve logo encaminhar os filhos na labuta da terra e nos cuidados com os animais, porque não adianta nada gastar tempo com estudo se o destino já está traçado. Para quem está condenado a brigar eternamente para manter o estômago cheio e as pernas firmes, dominar as letras é um luxo dispensável. Resigna-se Fabiano à sua condição miserável. Resigna-se ao fato de não ser fácil tirar a sobrevivência de uma terra onde prevalece a certeza de épocas ruins, da seca inevitável. Sua vida é uma eterna esperança de que, junto com a trovoada de dezembro, caia a chuva e que o sol poente tenha seu tom vermelho incandescente amenizado pelo verde da caatinga. Portanto, para que os meninos estudarem?

Importa saber que a maioria dos sertanejos até meados do século XX não frequentavam a escola e tinham suas relações circunscritas aos pais e aos irmãos no trabalho e no ambiente familiar, não experimentavam a convivência com grupo de iguais, formados por crianças de núcleos familiares distintos e que se agrupam dentro e fora da escola, desempenhando um papel importante, além da família, 
na socialização do indivíduo. O grupo de iguais é relevante para o aprendizado de normas e padrões de comportamento, uma vez que as crianças encontram satisfação de suas necessidades associativas no seu grupo etário, uma experiência marcante que influencia a formação de crenças e valores morais. De acordo com Argyle (1976, p. 73), abundam estudos que mostram a conformação das crianças às regras do grupo, regras estas que se originam nas "famílias de outros membros, professores e outros adultos ligados com o grupo. (...) As crianças aprendem as habilidades sociais de cooperação, a fazer amigos e influenciar pessoas, tanto pelo ensaio e erro quanto pela observação de outros membros do grupo."

Ao ser privado de relações sociais mais diversificadas, o sertanejo também enfrentava dificuldade para aprender a se comunicar verbalmente. O personagem Fabiano, do romance de Graciliano Ramos, grunhe, emite sons estranhos e formula frases ininteligíveis; imita os da cidade e repete suas palavras noutros contextos. Seu filho mais velho o reproduzia: "Como não sabia falar direito, o menino balbuciava expressões complicadas, repetia as sílabas, imitava os berros dos animais, o barulho do vento, o som dos galhos que rangiam na catinga, roçando-se." (RAMOS, 1988, p. 59).

$\mathrm{O}$ gênero de vida sertanejo anterior à urbanização estava estribado numa estrutura que o dispunha sobre o espaço físico de tal maneira que se encontrava em permanente contato com os membros da própria família e só eventualmente com os de outras, como nas ocasiões em que se reuniam para realizar a colheita e a farinhada, de sorte que as ações executadas com pessoas de outros domicílios constituíam uma exceção à regra. Portanto, é possível afirmar que o sertanejo vivia sob a influência do tipo puro de comunidade, que é a comunidade doméstica; segundo Weber (1991, p. 245), pode-se definila como "a comunidade econômica universalmente mais difundida e compreende uma ação comunitária muito intensa e contínua." Observando-se autoridade como sendo a do mais forte ou do mais experiente, que se realiza na prática enquanto autoridade dos homens 
sobre as mulheres e as crianças, bem como dos aptos e capazes para o trabalho sobre os incapazes, ou seja, dos adultos sobre as crianças.

Na comunidade doméstica sertaneja, cada um dos membros da família desempenhava um papel que se coadunava ao dos demais na consecução de atividades que objetivavam a manutenção de seus membros e, desse modo, os jovens eram orientados ainda em tenra idade. Essa característica desenvolve no indivíduo tanto uma dependência em relação aos outros membros da família como favorece o sentimento de pertença.

As crianças entre os seis e oito anos encontram-se num ambiente cultural, como descreve Arruda (2003), onde aprendem com os pais as atividades mais simples na agricultura e no trato dos animais. Assim como o lazer e o trabalho, os papéis sociais também se confundem no cotidiano sertanejo: num determinado momento de suas vidas, o sertanejo é pai-patrão-mestre de oficio, pois interage com os membros familiares, visando a diferentes objetivos, como o de manter a unidade familiar, garantir a produção dos bens necessários a sua reprodução e o de ensinar as tarefas da agricultura e do trato de animais aos filhos do sexo masculino. Isto "permite um exercício particularmente estreito e direto da ordenação social.” (MENDRAS, 1978, p. 89).

Enfim, é o pai que ensina as tarefas aos filhos, sendo estas, inclusive, uma característica universal do trabalho rural; contudo, a transferência de um valor cultural é outra peculiaridade presente na relação pai e filho, pois há entre os camponeses, como diz Redfield (1956, p. 23), "uma valorização tão positiva do trabalho que o define não apenas produtivo do ponto de vista material, mas também como cumprimento de uma ordem divina".

Os pais executam seu trabalho com rigor e ensinam os filhos a fazerem o mesmo. Esforçam-se para tornar seu comportamento uma referência que transmite o seguinte: ao trabalho o homem deve-se entregar com toda sua energia e sem cometer erros. Enfim, o que o pai do sertanejo almeja, ao lhe transmitir ensinamentos práticos, é inculcar-lhe a ideia de que, só por intermédio do trabalho, o indivíduo 
se torna alguém digno, uma pessoa merecedora de respeito. Numa palavra, a relação que o sertanejo mantém com seu pai na infância deve ser entendida, sobretudo, como um momento do processo de socialização, ou seja, canal por onde se efetiva a construção da identidade social do indivíduo.

Berger e Luckmann (2001) distinguem as formas de socialização primária e secundária. A socialização primária é o que torna um indivíduo membro de uma sociedade. De acordo com Dubar (1997), o seu mecanismo é constituído das relações entre o mundo social da família e o universo institucional da escola. E o aprendizado da fala, da leitura e da escrita são os saberes de base que permitem ao indivíduo apreender os modelos predefinidos de condutas sociais. Porém, é preciso considerar que, na zona rural do semiárido, até a primeira metade do século $\mathrm{XX}$, era restrito o acesso das crianças à escola; enfim, a socialização primária do sertanejo dava-se nomeadamente no âmbito da família.

Até meados do século XX, pode-se descrever a socialização primária na qual os sertanejos estavam inseridos, como uma sequência de aprendizado com três etapas que se distinguiam da seguinte forma: entre os cinco e os sete anos até, aproximadamente, os doze anos de idade, a criança acompanhava o pai que a ela ensinava o quanto era importante o indivíduo fazer o seu trabalho com afinco, ao realizar tarefas que prescindiam do uso de quaisquer instrumentos; após os doze anos, utilizavam enxadas e pás na plantação, mas eram ainda orientados no seu manejo pelos pais; a etapa seguinte era o desenvolvimento de atividades realizadas sem o acompanhamento dos pais, quando sozinhos passavam a tratar dos animais ou trabalhar num roçado, o que pressupunha a interiorização do trabalho como algo que deve ser realizado com responsabilidade (ARRUDA, 2003). A passagem para essa última etapa é decisiva na socialização do sertanejo, pois é aí que se conclui a sua socialização primária, na medida em que se forma na sua consciência o outro generalizado, que, de acordo com Berger e Luckmann (2001, p. 179), é quando ocorre 
“interiorização da sociedade enquanto tal e da realidade objetiva nela estabelecida e, ao mesmo tempo, o estabelecimento de uma identidade coerente".

Mas a socialização não é total nem finita, dado que o indivíduo está sujeito a socializações secundárias. Processo que ocupa um papel importante na formação da identidade social do indivíduo, haja vista que a sua efetivação acontece pela aquisição de saberes especializados, que Berger e Luckmann (2001) definem como conhecimento de funções específicas determinadas na divisão do trabalho. Esses saberes especializados se constituem na consciência do indivíduo tendo a socialização primária pressuposta, significando que as novas interiorizações ocorrem numa personalidade já formada. Decorre daí que se pode verificar um processo que vai da pura extensão da socialização primária até a possibilidade de uma mudança da realidade subjetiva apreendida nas interações com os membros da família de origem.

Atualmente, acompanhando o deslocamento do espaço onde se gera trabalho, ou seja, da zona rural para a zona urbana, o trabalho infantil está mais concentrado nas cidades, de sorte que, no Brasil, de um total de 2,7 milhões de crianças e adolescentes, segundo a Pesquisa Nacional de Amostra Domiciliar (PNAD), coordenada pelo Instituto Brasileiro de Geografia e Estatística (IBGE), em 2015, constatou-se que $68 \%$ estavam inseridos em atividades não-agrícolas e $32 \%$ em atividades agrícolas. Portanto, embora tenha ocorrido tal deslocamento, ainda restam muitas crianças realizando atividades no roçado e no trato de animais.

Há uma questão derivada das condições objetivas de reprodução do sertanejo que impulsiona o jovem para o trabalho ainda em tenra idade. Isso foi evidenciado por Eunice Durhan, quando pesquisou imigrantes nordestinos em São Paulo e concluiu acerca do trabalho infantil na área rural que: 
tipos diferentes de trabalhadores. (...) Deste modo, o aumento da produção só pode ser visto como resultado de um aumento de quantidade de trabalho, e não da transformação da qualidade do trabalho. Daí, inclusive, a depreciação da escola, que não constitui um instrumento de melhoria de vida, desde que não há, na sociedade rural, posições favoráveis a serem ocupadas pelo trabalhador escolarizado. (DURAN, 1973, p. 116).

Como o aumento da produção é resultado direto do aumento de trabalho e não do aprimoramento da técnica de produção, não há necessidade de que o jovem adquira conhecimento, pois é mais útil para o grupo familiar que ele ingresse mais rapidamente no trabalho. Contudo, questões ligadas à tradição também se encontram presentes na determinação do ingresso do jovem no mundo do trabalho. A idade de sete anos, como limite para o menino começar a trabalhar, está presa a uma lógica que antecede à da Idade Moderna.

Tal corte etário, que remonta à Antiguidade, fundou uma tradição nas sociedades pastoris e agrícolas da Idade Média. O intervalo de sete anos que classifica as idades provém da cultura clerical da Idade Média, período em que a simbologia dos números estava enraizada nas mentes populares. De acordo com Pastoureau (1996, p. 246), as taxinomias antigas distinguiam "a infantia (do nascimento aos sete anos), a pueritia (dos sete aos quatorze), a adulescentia (de quatorze a 21 ou 28 anos), a juventus (de 21 ou 28 a 35 anos), a virilitas (de 35 a 55 ou sessenta anos) e a senectus (acima de 55 ou sessenta anos)."

A necessidade de renda familiar acrescida ao costume de o jovem iniciar cedo no trabalho é o que ainda hoje faz que um contingente expressivo de crianças, no Brasil, insira-se tão precocemente no trabalho e que causa estranhamento naqueles já habituados com a classificação das idades apoiada na tradição das modernas sociedades industrializadas, em que o tempo para estudar se estende mais longamente, variando com cortes impostos pelo mercado de trabalho, alicerçados na necessidade de conhecimentos que deve ter o trabalhador para a operacionalização dos equipamentos e da adaptação às técnicas organizacionais. 
Mas não é só à tradição herdada da colonização que se deve creditar à prática da inserção precoce no mundo do trabalho, pois, ciente disso, há que se considerar que, na zona rural, muitas crianças ainda não dispõem de escola próxima ao lugar de residência nem possibilidade de deslocamento para vilas e cidades, onde mais frequentemente se localizam. A educação deve ser enfatizada nesta discussão, porque, com ela, segmentou-se o tempo do indivíduo assentado numa lógica diferente da elaborada no Medievo; com a educação, institucionalizou-se o tempo de brincar, de aprender e de trabalhar, sabe-se onde encerra a infância e tem início a juventude. É com a obrigatoriedade escolar, de acordo com Schindler (1996, p. 271), que se "estabelece uma clara demarcação entre infância e juventude no momento da conclusão dos estudos, do início da aprendizagem e ingresso no mundo do trabalho”.

\section{REGULAÇÃO DO TRABALHO INFANTIL NO BRASIL}

O trabalho infantil é realidade em vários lugares do mundo, entretanto, sua incidência é observada com maior frequência nos países periféricos e semiperiféricos, pois está intimamente relacionado à pobreza e à exclusão social. Infelizmente, apesar das inumeráveis ações estatais já realizadas, essa tipologia de trabalho, renitentemente, aparece nos dados coletados pelo Instituto Brasileiro de Geografia e Estatística (IBGE). Conceitualmente, pode-se caracterizar o trabalho infantil, segundo Cavalcante (2011, p. 27), como "aquele realizado por crianças e adolescentes que estão abaixo da idade mínima para a entrada no mercado de trabalho, segundo a legislação em vigor no país."

A denúncia das más condições de sobrevivência das crianças e dos adolescentes remonta aos anos 30, quando o romance regionalista deu visibilidade ao tema na cidade e no campo, como na obra Capitães da Areia, de Jorge Amado, e da supracitada, Vidas Secas, de 
Graciliano Ramos. Entretanto, o tema trabalho infantil ganhou relevância no mundo acadêmico com aumento das pesquisas nas ciências sociais, o que conduziu a iniciativas político-jurídicas de relevância, ao associar o combate ao trabalho infantil às questões concernentes à redução da pobreza e à melhoria das condições gerais de sobrevivência da população. Outrossim, foram importantes as análises econômicas sobre o assunto, porque se buscou estudar quais elementos levavam ao progresso econômico, sendo o trabalho de crianças e adolescentes visto como um impedimento ao desenvolvimento e, consequentemente, obstáculo à redução de pobreza e ao aumento de capital humano. (KASSUOF, 2017).

Neste sentido, a luta pela erradicação do trabalho infantil, em última instância, trata-se de proteção à vida do infante, uma vez que se está diante de um sujeito consensualmente apreendido enquanto sujeito que é objeto de proteção por se encontrar em condições de desenvolvimento físico, psicológico, espiritual, moral e social. Como sintetiza Buarque (2015, p. 30), "o trabalho precoce impede o desenvolvimento da criança, afasta-a da escola, dificulta seu aprendizado, prejudica seu desenvolvimento pleno, causa danos físicos ou psicológicos, que podem persistir por toda a vida." Nessa acepção, o trabalho infantil viola princípios dos direitos humanos, como o da dignidade da pessoa humana.

Para Hoefel (2015), o trabalho infantil é uma estratégia empregada para promover a redução de custos e aumento de receitas. Uma prática que expõe crianças ou adolescentes a riscos de acidentes, a esforços excessivos, bem como a substâncias nocivas à saúde, afetando o seu organismo que está em fase de amadurecimento, e prejudica também o desenvolvimento afetivo e cognitivo, em função do abandono das atividades escolares.

Esses prolegômenos explicitam o quadro geral sobre o qual se assenta a legislação direcionada à proteção das crianças e dos adolescentes prevista na Constituição Federal de 1988. Em seu art. 227, por exemplo, alude a necessidade da proteção integral do incapaz, 
determinando que:

É dever da família, da sociedade e do Estado assegurar à criança, ao adolescente e ao jovem, com absoluta prioridade, o direito à vida, à saúde, à alimentação, à educação, ao lazer, à profissionalização, à cultura, à dignidade, ao respeito, à liberdade e à convivência familiar e comunitária, além de colocá-los a salvo de toda forma de negligência, discriminação, exploração, violência, crueldade e opressão.

No art. $7^{\circ}$, XXXIII, do mesmo Diploma Legal, está prevista a proibição do trabalho noturno, perigoso ou insalubre para menores de 18 anos, e de qualquer trabalho para menores de 16 anos, salvo na condição de aprendiz, a partir dos 14 anos. Restam consagrados princípios constitucionais que resguardam o direito do infante, dentre eles o princípio constitucional da dignidade da pessoa humana, previsto no art. $1^{\mathrm{o}}$, inciso III, característica própria de todo ser humano, que fundamenta ser os infantes sujeitos que necessitam de um resguardo especial da sociedade, do Estado e da família, para que possam se desenvolver de modo satisfatório.

Ressaltem-se ainda os princípios do melhor interesse da criança e o da proteção integral ou prioridade absoluta previstos na Constituição Federal, decorrentes do art. 227, que colocam os interesses das crianças e dos adolescentes como prevalecentes para a interpretação da lei, para a solução de conflitos e para elaboração de ações públicas (AMIN, 2010). Vê-se, assim, como explica Saraiva (2020), que, a partir da promulgação da Constituição Federal de 1988, as crianças e os adolescentes tornaram-se prioridade absoluta, sendo dever da família, da sociedade e do Estado protegê-los. O entendimento em referência é compartilhado por Liberati (2003), ao defender com veemência que:

Por absoluta prioridade, entende-se que, na área administrativa, enquanto não existirem creches, escolas, postos de saúde, atendimento preventivo e emergencial às gestantes, dignas moradias e trabalho, não se deverão asfaltar ruas, construir praças, sambódromos, monumentos artísticos, etc., porque a vida, a saúde, o lar, a prevenção de doenças são mais importantes que as obras de concreto, que ficam para demonstrar o poder do 
governante. (LIBERATI, 2003, p.47).

O Estatuto da Criança e do Adolescente (ECA), Lei no 8.069 de 1990, no Art. 60 a 69, regula o trabalho da infância e da juventude com base na proteção integral dada aos infantes, ou seja, implementa uma verdadeira rede de proteção, com a finalidade de resguardar os direitos de tais sujeitos. Ressalte-se, como pontilha Amin (2010), que o seu surgimento se alicerça na necessidade que se impunha de reparação dos danos causados com a legislação anterior, o Código de Menores, Lei $n^{0} 6.697 / 79$, que tratava as crianças e os adolescentes como objetos de medidas judiciais e não como sujeitos de direitos, além de estar centrado na situação irregular, ou seja, intencionava afastar da sociedade o jovem infrator.

O Estatuto da Criança e do Adolescente (ECA) é fundado em três pilares principais, ou seja, o reconhecimento da condição especial da criança, que se encontra em fase de desenvolvimento; a percepção de que as crianças e os adolescentes passam a ser sujeitos de direito, assim deixando de ser objetos passivos; e, por fim, tais sujeitos são carecedores de proteção singular, pois se deve preservar o direito ao convívio familiar. (PAUL, 2017).

A proteção dada ao infante, pelo ECA, foi endossada pela Convenção Internacional sobre os Direitos da Criança, considerada instrumento de ruptura com a legislação "menorista", mencionada anteriormente, pois está alicerçada nas normas internacionais sobre direitos humanos. Segundo Paul (2017, p. 941), “a Lei n. 8.069/90 do ECA consolidou uma grande conquista da sociedade brasileira contemplando o que há de mais avançado na normativa internacional em respeito aos direitos da população infanto juvenil”.

A Consolidação das Leis do Trabalho (CLT) também dispõe do tema em seu Capítulo IV, da proteção ao menor, que trata das condições necessárias para o trabalho do adolescente menor de 18 anos. No Decreto 6.481, de 2008, elenca as formas degradantes de trabalho infantil, indicando várias atividades consideradas perigosas ou insalubres, que são proibidas para menores de 18 anos. 
Por sua vez, a Lei $\mathrm{n}^{0}$ 8.742, de 1993, conhecida como Lei Orgânica de Assistência Social (LOAS), regulamenta os artigos 203 e 204 da Constituição Federal, que determina a proteção social dos grupos mais vulneráveis da população, via promoção de benefícios, programas sociais, entre outros, sendo a proteção dada à infância e à adolescência prevista no art. $2^{\circ}$, I e II.

Vale ainda ressaltar que o Brasil é signatário de vários documentos internacionais, sendo importante destacar as Convenções da Organização Internacional do Trabalho (OIT) n ${ }^{0}$ 182, de 1999 e a de $\mathrm{n}^{0} 138$, de 1973, que foram ratificadas pelo Brasil em 2002. Tais Convenções têm por objeto o infante, tratando a primeira das formas degradantes de trabalho infantil, apontando atividades proibidas e determinando soluções para a erradicação; enquanto a segunda discrimina a idade mínima para o trabalho, levando em consideração a saúde e a escolaridade necessárias para o seu desenvolvimento pleno e saudável.

A OIT editou nove convenções sobre trabalho infantil, tendo o Brasil ratificado apenas seis. Além das duas acima mencionadas, podese citar ainda as Convenções 6, 7, 16 e 124, ratificadas pelo Brasil, que tratam, respectivamente, do trabalho noturno dos menores na Indústria, da idade mínima para admissão no trabalho marítimo, do exame médico de menores para o trabalho marítimo e trabalho subterrâneo nas minas (OIT, 2019). Para Marques (2013, p. 206), Procurador do Trabalho, Coordenador da Coordenadoria Nacional de Combate à Exploração do Trabalho de Crianças e Adolescentes, as Convenções Internacionais que tratam sobre trabalho infantil objetivam proteger crianças e adolescentes "da gana capitalista, ceifadoras de suas condições peculiares de seres em desenvolvimento, para encará-las como fonte de mão de obra, garantindo-lhes condições para o pleno desenvolvimento físico, moral, intelectual e psicológico."

Além da legislação aludida, menciona-se outros diplomas legais tratando sobre trabalho infantil, dentre eles a Lei de Diretrizes e Bases da Educação (LDB), o Código Penal (Lei n ${ }^{\circ}$ 2848/1940) e o Estatuto da Juventude (Lei Federal No 12.852/20135). Outrossim, vale 
ressaltar a importância da participação dos Conselhos Tutelares e dos Fóruns de Direitos da Criança e do Adolescente na busca pela erradicação do trabalho infantil, visto que visam a mobilizar e a sensibilizar a sociedade civil sobre a questão.

Veronese (2013) explicita que tanto os dispositivos presentes no texto constitucional quanto os instituídos via legislação ordinária, em especial a Lei No. 8.069/9o, buscam contribuir para a estruturação de uma organização social indutora da construção e do fortalecimento das instâncias viabilizadoras do desenvolvimento de seus membros. Mas, infelizmente, o diagnóstico da autora aponta que o país está assentado num modelo societário que não valoriza a associação fraterna.

Em suma, a legislação vigente se depara com uma realidade a qual se encontra fortemente enraizado à legitimidade social do trabalho infantil, que é corroborado com limites reais de sobrevivência impostos às famílias de baixa renda que forçam os filhos a abandonar a escola. Com efeito, as altas taxas de desistência do ensino formal que atinge o Brasil alcança vários países, principalmente aqueles empobrecidos e com má distribuição de renda. Não é ao acaso, portanto, que se construíram vários acordos internacionais na defesa dos interesses da criança e do adolescente com relação ao trabalho.

\section{PROJETO DE COOPERAÇÃO ALGODÃO COM TRABALHO DECENTE: UMA REFLEXÃO CRÍTICA}

O cultivo do algodão, um dos produtos agrícolas mais importantes, tendo em vista a sua utilização por diversos setores da economia, é praticado também pela agricultura familiar, ou seja, por pequenos produtores. Tal produção contribui de maneira efetiva para o acesso a alimentos, à moradia e a outros bens necessários à subsistência do agricultor e de sua família. De acordo com Beltrão (1997), o Brasil, até 1986, produzia uma quantidade superior de 
algodão à sua demanda interna, mas em função da falta de apoio estatal, para o enfrentamento de alguns problemas de ordem técnica e estrutural, a produção retroagiu no ano de 1993 e alcançou o total de 416.ooot, para um consumo de 763.ooot. Apesar de o país não ser mais um exportador dessa matéria prima, a demanda interna estimula uma produção que ocupa área considerável e emprega um número substancial de pessoas.

Infelizmente, assim como outros produtos agrícolas, a cotonicultura emprega mão de obra infantil, violando direitos constitucionais e causando danos, como já anteriormente assinalados, para tal segmento populacional residente nas áreas rurais. Destarte, o projeto de Cooperação Algodão com Trabalho Decente, executado pela Organização Internacional do Trabalho, em parceria com a Agência Brasileira de Cooperação ( $\mathrm{ABC}$ ) e o Instituto Brasileiro do Algodão (IBA), tem por finalidade a promoção de melhorias das condições de trabalho no setor algodoeiro, mais precisamente nos países da África e da América Latina, por intermédio do compartilhamento e da adaptação de experiências positivas e relevantes (OIT, 2017).

O projeto tem duração prevista de 54 meses, de maio de 2015 a novembro de 2019; no entanto, o seu início formal ocorreu em 2009, com a aprovação do Ajuste Complementar ao Acordo de Cooperação Técnica com Países da América Latina e da África. Sua elaboração foi decorrente de questões consideradas essenciais para a OIT, pois intenciona a erradicação do trabalho infantil e do trabalho forçado na indústria da cotonicultura. A partir daí, buscaram-se os países produtores de algodão que tinham ocorrência dos problemas elencados acima e que gostariam de participar da iniciativa, assim foram selecionados selecionado Brasil, Paraguai, Peru, Moçambique, Mali e Tanzânia (OIT, 2015).

$\mathrm{O}$ projeto elenca como membros constituintes diretos as instituições governamentais, as organizações de trabalhadores e os empregadores dos países em desenvolvimento produtores de algodão e como indiretos as crianças, os adolescentes, as mulheres e as famílias dos produtores de algodão nos países participantes do projeto. São 
vários os temas tratados no projeto, dentre outros, destaque-se o combate à pobreza, à erradicação do trabalho infantil e do trabalho forçado, bem como o incentivo à formalização do trabalho, à promoção do emprego de jovens em idade para trabalhar. O projeto tem relevância no âmbito do território brasileiro, dado sua importância para a promoção do desenvolvimento e para a efetivação dos direitos fundamentais dos infantes:

No Brasil, por exemplo, o trabalho infantil na produção de algodão está virtualmente erradicado, principalmente como resultado da atuação da inspeção do trabalho e do desenvolvimento de processos de certificação do algodão. Mas, infelizmente, este e outros problemas ainda persistem em outros países. Por isso, a Cooperação Sul-Sul é fundamental para compartilhar com esses países as possíveis soluções encontradas pelo Brasil. (OIT, 2017, p. 2.)

No Brasil, portanto, o trabalho infantil rural na cadeia produtiva do cultivo do algodão diminuiu consideravelmente, tendo se tornado referência para outros países em que a sua incidência ainda é elevada, como é o caso do Paraguai, do Peru, de Mali, de Moçambique e da Tanzânia. Com efeito, a prevenção e a eliminação do trabalho infantil e do trabalho forçado na cotonicultura é uma das experiências brasileiras mais exitosas e digna de ser compartilhada no projeto com os demais países.

Destarte, foram selecionadas as seguintes políticas públicas brasileiras: programas de transferência de renda condicionada; programas de reintegração de vítimas do trabalho forçado e infantil; promoção do diálogo social; Comissão Nacional de Erradicação do Trabalho Infantil (CONAETI) e Comissão Nacional para a Erradicação do Trabalho Escravo (CONATRAE)); a inspeção do trabalho nos temas de trabalho infantil e trabalho forçado; promoção da legislação trabalhista nacional e internacional, com aproximação entre o Poder Judiciário e a sociedade; e, por fim, a Experiência da Associação Brasileira dos Produtores de Algodão (ABRAPA) (OIT, 2017).

As políticas de prevenção e eliminação do trabalho infantil e 
forçado são programas de transferência de renda condicionada e programas de reintegração de vítimas de trabalho forçado e/ou infantil. O Bolsa Família, por exemplo, é uma ação pública social voltada para transferir renda para famílias extremamente pobres, com a finalidade de garantir renda de modo imediato, com o intuito de amenizar a pobreza e a vulnerabilidade. No Brasil, são 13.9 milhões de brasileiros beneficiados com o programa social (ARAÚJO, 2016).

Já o Programa de Erradicação do Trabalho Infantil (PETI) traz várias ações voltadas para o público infanto juvenil com o propósito de retirá-lo do trabalho precoce, compreendendo campanhas de conscientização, transferência de renda, acompanhamento de equipe profissional às crianças e aos adolescentes e para suas respectivas famílias, oferta de serviços assistenciais, entre outras atuações (ARAÚJO, 2016).

Outrossim, a Comissão Nacional para a Erradicação do Trabalho Infantil (CONAETI) e a Comissão Nacional para a Erradicação do Trabalho Escravo (CONATRAE) são exemplos de experiências de diálogo social relevantes. A CONAETI é um órgão criado a partir da Portaria $\mathrm{n}^{0} 365$, de 12 de setembro de 2002, coordenado pelo Ministério do Trabalho e Emprego, e possui participação quadripartite, ou seja, há representantes do governo, empregadores, empregados e sociedade civil. A atribuição principal da CONAETI foi a elaboração do Plano Nacional de Prevenção e Erradicação do Trabalho Infantil e Proteção ao Trabalhador Adolescente, em 2003. Nos termos do art. $1^{\circ}$ da Portaria MTE $n^{0}$ 952, de 8 de julho de 2003, é competência da CONAETI:

Art. $1^{\mathrm{o}}$ Instituir, no âmbito do Ministério do Trabalho e Emprego, a Comissão Nacional de Erradicação do Trabalho Infantil - CONAETI, com as seguintes atribuições: I - elaborar proposta de um Plano Nacional de Combate ao Trabalho Infantil; II - verificar a conformidade das Convenções Internacionais do Trabalho 138 e 182 com outros diplomas legais vigentes, elaborando propostas para a regulamentação de ambas e para as adequações legislativas porventura necessárias; III avaliar as atividades constantes da Portaria $n^{\circ} 20$, de 13 de setembro de 2001, alterada pela Portaria $n^{0} 4$, de 21 de março de 2002; IV - propor mecanismos para o monitoramento da aplicação da Convenção 182; e V - 
coordenar, monitorar e avaliar a execução do Plano Nacional de Erradicação do Trabalho Infantil e Proteção do Trabalhador Adolescente, competindo-lhe apresentar anualmente, até o mês de dezembro, propostas de modificações. (Inciso acrescentado pela Portaria MTE $\mathrm{n}^{\mathrm{o}}$ 356, de 13.07.2004, DOU 14.07.2004). (BRASIL, 2004).

Já a CONATRAE é um órgão colegiado que foi criado em 31 de julho de 2003, sendo vinculado ao Ministério dos Direitos Humanos da Presidência da República, composto por representantes dos três Poderes, além de vários outros representantes da sociedade civil, e presidida pelo Ministro de Estado dos Direitos Humanos. O objetivo da CONATRAE é "coordenar e avaliar a implementação das ações previstas no Plano Nacional para a Erradicação do Trabalho Escravo". Saliente-se que compete à Comissão acompanhar a tramitação de projetos de lei no Congresso Nacional e avaliar a proposição de estudos e pesquisas sobre o trabalho escravo no país (BRASIL, 2003).

Os programas de Comissão Nacional para a Erradicação do Trabalho Infantil (CONAETI) e de Comissão Nacional para a Erradicação do Trabalho Escravo (CONATRAE) promovem o diálogo social e favorecem a criação de instrumentos de erradicação dos seus respectivos temas. As boas práticas de inspeção do trabalho, no Brasil, realizadas pelo Governo Federal, através do Ministério do Trabalho e Emprego (MTE) e da Secretaria de Inspeção do Trabalho (SIT), podem ser consideradas relevantes para serem reaplicadas a outras realidades pela sua pertinência e impacto. As fiscalizações são articuladas de modo que contribuem para a melhoria das condições de trabalho.

A Associação Nacional dos Magistrados do Trabalho (ANAMATRA) desenvolve o Programa Trabalho, Justiça e Cidadania (TJC), criado em 2004, para difundir e esclarecer as dúvidas sobre questões envolvendo direitos básicos garantidos pela Constituição Federal, além de direitos específicos trabalhistas dos indivíduos e sobre acesso à Justiça, promovendo assim a cidadania. Os objetivos do TJC são estimular a conscientização dos direitos e dos deveres básicos do cidadão, desenvolver a integração do Judiciário com a sociedade e promover a qualificação do exercício da cidadania. Vale ainda ressaltar 
que o público alvo primário do Programa é composto por estudantes do ensino fundamental e médio, que estão em formação para ingressar no mercado de trabalho; bem como por estudantes dos cursos profissionalizantes, escolas de jovens e adultos (EJAS) e professores. Já o público alvo secundário é composto por servidores públicos do Judiciário, estudantes de Direito, entidades da sociedade civil e a população em geral (ANAMATRA, 2013).

Por fim, cumpre relatar a experiência da Associação Brasileira dos Produtores de Algodão (ABRAPA) no desenvolvimento do Programa Algodão Brasileiro Responsável-ABR, que venceu, em 2014, o prêmio República de Valorização do Ministério Público Federal, promovido pela Associação Nacional dos Procuradores da República (ANPR), na categoria responsabilidade social. A ABRAPA foi criada em 7 de abril de 1999, com o propósito de unir os agentes produtores da cotonicultura na busca pela sustentabilidade, ambiental social e econômico, e maior rentabilidade, junto aos setores públicos e privados, sendo fomentadora da melhoria da produção do algodão no Brasil (ABRAPA, 2019).

O Programa Algodão Brasileiro Responsável-ABR tem como principais objetivos a promoção da evolução progressiva das boas práticas da sustentabilidade, com o intuito de construir uma imagem relevante do cenário brasileiro no exterior e, consequentemente, conquistar o mercado internacional; a melhoria da gestão sustentável das unidades produtiva; e a disseminação entre os associados dos três pilares da sustentabilidade: social, ambiental e econômico (ABRAPA, 2019).

Em 2014, a ABRAPA iniciou as mobilizações do Programa ABR (Algodão Brasileiro Responsável), em parceria com as associações estaduais, para a safra 2014/15. A mobilização era o momento destinado à obtenção, pelos produtores, de orientações acerca da aderência ao Programa, os passos a serem cumpridos, entre outros requisitos. A verificação é realizada por técnicos da associação, de acordo com a OIT (2015, p. 5), com base em 8 critérios de certificação: "contrato de trabalho; proibição de trabalho infantil; proibição de 
trabalho análogo a escravo, degradante ou indigno; liberdade de associação; não discriminação; segurança, saúde e meio ambiente do trabalho; responsabilidade ambiental; boas práticas agrícolas."

Observe-se, ainda, que a participação no projeto coordenado pela OIT contribui também para a erradicação de formas de trabalho, as quais são consideradas graves violadoras dos direitos humanos e dos direitos e princípios fundamentais do trabalho e praticadas em outros setores econômicos. Uma vez que conduz a conscientização de agentes públicos e das famílias dos efeitos nefastos das atividades degradantes e da inserção precoce no mercado de trabalho, o que vai de encontro ao imaginário popular de que os filhos das famílias mais pobres devem trabalhar para ajudar na renda da família, já que, mantendo-se ocupados, não representam perigo à sociedade, por meio de cometimento de crimes. (COLUCCI, 2013).

O Brasil, apesar de ter se tornado referência internacional, em função das ações exitosas de combate ao trabalho infantil, como mostra o projeto de Cooperação Sul-Sul Algodão com Trabalho Decente, ainda tem muito a realizar, pois são recorrentes os casos de identificação de crianças e adolescentes em situações de risco, como a exploração sexual, os trabalhos tanto em casa quanto nas ruas em condições assemelhadas à escravidão.

No campo, o trabalho realizado pelas crianças e pelos adolescentes é prioritariamente voltado para a agricultura familiar, sendo, muitas vezes, isento de remuneração. O Nordeste brasileiro pode ser visto como a região mais crítica já que possui 15,9\% de jovens até 17 anos no labor, segundo dados do IBGE. (RODRIGUES, 2016).

A região Nordeste ainda detém o maior número de crianças e adolescentes trabalhando, na faixa etária de 5 a 15 anos, em situações, muitas vezes, consideradas pela lei como as piores formas de trabalho infantil (KASSOUF, 2004). De acordo com dados coletados na Pesquisa Nacional de Amostras de Domicílio (PNAD), realizada em 2001, na região Nordeste, observa-se incidência de trabalho infantil mais elevada em comparação com as demais regiões do País, sendo tal 
proporção "atribuída ao fato de esta região deter os piores indicadores educacionais e ser também a que possui maior número de pobres, determinantes principais do trabalho infantil." (KASSOUF, 2004, p. 25).

Os dados indicam que se pode associar a incidência elevada de trabalho infantil a deficiências na elaboração e/ou na execução de políticas públicas elementares, como educação, saúde e saneamento. As políticas econômicas adotadas para a região também trazem implicações, na medida em que criam e robustecem o distanciamento entre as classes sociais, provocam concentração de renda e desemprego, condições que afetam diretamente a estrutura familiar das classes mais desfavorecidas, que, por necessidade de sobrevivência, optam por colocar todos os membros da família em atividades laborais no intuito de formar renda.

Para Kassouf (2004), os fatores relacionados à sobrevivência são de fato determinantes para o ingresso da criança no mercado de trabalho. Tal fenômeno ocorre porque, frequentemente, as crianças se encontram numa espiral de pobreza, em que os pais sem escolaridade, sem qualificação profissional, detêm uma renda miserável e se encontram em situação de pobreza; assim se reproduzem socialmente, condenando as gerações subsequentes a viverem em condições assemelhadas aos dos pais, ou seja, sem renda digna, sem usufruir de lazer e sem escolaridade.

As dificuldades socioeconômicas da região Nordeste em relação às outras regiões, em virtude de condicionantes históricas; os fatores climáticos, como estiagens prolongadas e terras de baixa produtividade, corroboram com o baixo crescimento econômico. De acordo com Sousa et all (2018), as ações públicas de desenvolvimento concentraram-se no fomento do crescimento econômico, pelo investimento de capital, tendo sido inspirada nas teorias dominantes pós Segunda Guerra Mundial. Souza et all (2018) detalha a crença de que a intensidade do capital seria suficiente para realizar o desenvolvimento o qual se fundamenta nos programas de financiamento das organizações internacionais direcionados aos 
países subdesenvolvidos; infelizmente, essa estratégia se mostrou ineficiente e não foi capaz de alterar a realidade traduzida nos indicadores sociais e econômicos, conduzindo ao entendimento de que a estatal alicerçada na inversão de capital não é suficiente para proporcionar desenvolvimento a longo prazo.

Compreende-se, atualmente, que as políticas públicas de incentivo ao desenvolvimento devem, além do investimento em capital, focar no incremento do capital humano, por intermédio de capacitação da força de trabalho, desenvolvimento da educação, aumento de pesquisas tecnológicas, entre outros fatores. A intelecção reportada conduz a sublinhar a ideia de que o desenvolvimento depende da intervenção do Estado, como defendem Gunnar Myrdal (1965) e Amartya Sen (2000), pensadores laureados com o prêmio Nobel. Destarte, além do crescimento econômico, elementos como qualidade de vida da população, distribuição de renda, oferta de empregos, liberdade desfrutada pelos membros da sociedade contribuem para o pleno desenvolvimento.

O Projeto de Cooperação Algodão com Trabalho Decente salientou a existência, no Brasil, de práticas exitosas de promoção do trabalho decente e erradicação do trabalho infantil no setor produtivo de algodão. Com efeito, o projeto sublinha que o país contribui para a promoção do trabalho digno com ênfase nos direitos fundamentais do trabalho e para a melhoria das condições de trabalho em países em desenvolvimento.

A indicação das políticas brasileiras, como exemplos a serem seguidos, está associada à avaliação das práticas, que têm avançado e não se limitado a investimento exclusivamente de capital. Assim, a Organização Internacional do Trabalho (OIT) recomenda a adaptação das políticas, salientando a necessidade de adaptação às realidades concretas e ao envolvimento ativo dos interessados. Assim se incentiva o diálogo para a troca de experiências e buscado ampliar, entre os países que desenvolvem a cotonicultura, a conscientização dos problemas que o trabalho infantil desencadeia. 
Apesar dos bons resultados obtidos com o projeto, ainda se observa uma forte inserção de crianças e adolescentes no mercado de trabalho. É mister que políticas públicas destinadas ao combate do trabalho infantil sejam concebidas e executadas. Outrossim, programas como o do Projeto de Cooperação Sul-Sul Algodão com Trabalho Decente devem ser estudados e adaptados para o combate de outras modalidades de trabalho infantil, assim fomentando um processo de conscientização da sociedade.

\section{CONSIDERAÇÕES FINAIS}

O projeto de Cooperação Algodão com Trabalho Decente identificou ações públicas praticadas no Brasil que impactaram positivamente a cotonicultura no que se refere à inibição do trabalho infantil. As experiências reportadas foram alçadas à condição de referências e, portanto, compartilhadas com os demais países que fazem parte desse projeto concebido e gerenciado pela Organização Internacional do Trabalho (OIT).

Observou-se que, para se alcançar resultados concretos concernentes à redução da participação de crianças e adolescentes na produção algodoeira, faz-se necessário que as políticas de desenvolvimento não sejam centradas exclusivamente na inversão de capital, mas promova um diálogo com todos os interessados, que se encontram de um extremo ao outro da cadeia produtiva, no sentido de identificar com precisão as carências, principalmente dos produtores diretos, de sorte que deva ser averiguado o acesso à saúde, à educação, à alimentação, dentre outras necessidades básicas. Salienta-se que é imprescindível porque existe uma relação direta do índice de pobreza da população com a inserção precoce dos jovens no mercado de trabalho.

O trabalho infantil se trata de um obstáculo ao desenvolvimento 
físico, psíquico e moral do infante; sem dúvida, no médio e longo prazo, funciona para impedir o progresso socioeconômico, uma vez que os sujeitos imersos nessa condição são impedidos de se profissionalizar; assim, reproduzem-se como seus antecedentes, ou seja, com baixa escolaridade, em trabalhos precários e situação de pobreza.

A ideia de que o indivíduo se torna pessoa digna por intermédio do trabalho está enraizada na formação cultural brasileira. É renitente no consciente coletivo o pensamento de que se faz necessário inserir o jovem em atividade laboral, com o objetivo de mantê-lo afastado da delinquência, cujo pensamento domina a opinião pública, principalmente quando se trata de crianças originárias de famílias de baixa renda. Não é ao acaso, portanto, que ainda hoje se encontre um maior número de crianças trabalhando na região Nordeste, pois combina-se nesse espaço a formação cultural fortemente fincada no trabalho campesino, uma forte desigualdade de renda e, consequentemente, um número substancial de famílias na condição de pobreza.

Apesar dos avanços registrados no concernente ao combate ao trabalho infantil, como observado pelo projeto de Cooperação Algodão com Trabalho Decente, faz-se mister o contínuo aperfeiçoamento das políticas públicas adotadas, pois é preciso alargar entre os membros da sociedade a conscientização dos problemas gerados pelo trabalho das crianças e dos adolescentes para o desenvolvimento, tanto do sujeito colocado em tal situação quanto da região que abriga o trabalho infantil. Enfim, urge construir uma rede de proteção às crianças que se alicerce no combate ao senso comum que valida moralmente a inserção precoce no mercado de trabalho, mas deve-se seguir com o fortalecimento normativo e com a execução de ações estatais direcionadas para essa questão social. 
Data de Submissão: 21/03/2019

Data de Aprovação: 16/12/2019

Processo de Avaliação: double blind peer review

Editor Geral: Jailton Macena de Araújo

Editor de Área: Jailton Macena de Araújo

Assistente Editorial: Bruna Agra de Medeiros

\section{REFERÊNCIAS}

ABRAPA- Associação Brasileira dos Produtores de Algodão. Brasília, 2019. Disponível em:

http://www.abrapa.com.br/Paginas/sustentabilidade/algodaobrasileiro-responsavel.aspx. Acesso em: 02 fev. 2019.

AMADO, Jorge. Capitães da Areia. São Paulo: Companhia das Letras, 2017.

AMIN, Andréa Rodrigues. Princípios orientadores do direito da criança e do adolescente. In: MACIEL, Kátia Regina Ferreira Andrade. Curso de Direito da Criança e do Adolescente: aspectos teóricos e práticos. São Paulo: Lumen Juris, 2010.

ANAMATRA- Associação Nacional dos Magistrados do Trabalho. Trabalho, Justiça e Cidadania. Brasília, 2013. Disponível em: https://www.anamatra.org.br/attachments/article/55/apresentacao tjc 2013.pdf. Acesso em: O5 fev. 2019.

ARAÚJO, Danielle Ferreira Medeiro da Silva de. Trabalho infantil: desafios para a superação de uma norma social no Brasil. Cadernos de Ciências Sociais Aplicadas. Vitória da Conquista, 2016. Ano XIII, n. 21, p.69-83. Disponível em:

http://periodicos.uesb.br/index.php/cadernosdeciencias/article/vie wFile/6481/pdf 388. Acesso em: 03 fev. 2019.

ARGYLE, Michael. A interação social: relações interpessoais e comportamento social. Rio de Janeiro: Zahar Editores, 1976.

ARRUDA, Gerardo Clésio Maia. Andarilhos do sertão: a mudança do padrão de comportamento do trabalhador rural na cidade do semiárido nordestino. Fortaleza:

Universidade Federal do Ceará (UFC), Tese de Doutorado, 2003. 
Políticas Públicas De Erradicação Do Trabalho Infantil: Uma Reflexão Apoiada No Projeto...

BERGER, Peter L. e LUCKMANN, Thomas. A construção social da realidade. Petrópolis: Vozes, 2001.

BRASIL. Consolidação das Leis do Trabalho (CLT).

http://www.trtsp.jus.br/geral/tribunal2/LEGIS/CLT/capa clt dina mica.htm. Acesso: 05/01/2019.

BRASIL. Constituição Federal de 1988.

http://www2.planalto.gov.br/conheca-a-

presidencia/acervo/constituicao-federal. Acesso: 10/01/2019.

BRASIL. Estatuto da Criança e do Adolescente (ECA).

http://www.conselhodacriança.al.gov.br/sala-de-

imprensa/publicações/ECAATUALIZADO.pdf. Acesso: 10/01/2018.

BRASIL. Instituto Brasileiro de Geografia e Estatística (IBGE).

Pesquisa Nacional de Amostra Domiciliar (PNAD), 2001.

http://ww2.ibge.gov.br/home/presidencia/noticias/imprensa/ppts/ o0000010135709212012572220530659.pdf. Acesso: 14/01/2019.

BRASIL. Instituto Brasileiro de Geografia e Estatística (IBGE).

Pesquisa Nacional de Amostra Domiciliar (PNAD), 2015.

http://ww2.ibge.gov.br/home/estatistica/pesquisas/pesquisa result ados.php?id pesquisa=40. Acesso: 20/12/2018.

BRASIL. Ministério da Mulher, da Família e dos Direitos Humanos.

Comissão Nacional para a Erradicação do Trabalho

Escravo. Brasília, 2003. Disponível em:

http://www.mdh.gov.br/informacao-ao-cidadao/participacao-

social/orgaos-colegiados/conatrae/comissao-nacional-para-a-

erradicacao-do-trabalho-escravo. Acesso em: 05 fev. 2019.

BUARQUE, Cristovam. Trabalho infantil: realidade e perspectivas.

Revista do Tribunal do Superior do Trabalho. Rio de Janeiro:

Imprensa Nacional, v. 81, n. 1, p. 30-39, jan/mar, 2015.

CAVALCANTE, Sandra Regina. Trabalho infantil artístico: do deslumbramento à ilegalidade. São Paulo: LTr, 2011.

COLUCCI, Viviane. A teoria da proteção integral frente ao combate ao trabalho infantil e à regularização do trabalho do adolescente.

Revista do Tribunal Superior do Trabalho. Rio de Janeiro:

Imprensa Nacional, vol. 79, n.1, p. 55-65, jan/mar, 2013.

DUBAR, Claude. A socialização: construção das identidades sociais e Profissionais. Porto: Porto Editora, 1997.

HOEFEL, Maria da Graça Luderitz. Danos à saúde física e mental: prejuízo irrecuperável. Revista do Tribunal do Superior do Trabalho. Rio de Janeiro: Imprensa Nacional, v. 81, n. 1, p. 71-77, jan/mar, 2015 . 
INEP. Censo escolar 2016. Brasília: Ministério da Educação (MEC), 2016. www.portal.mec.gov.br/docman/fevereiro-2017pdf/59931-app-censo-escolar-da-educacao-basica-2016-pdf-1/file. Acesso: 14/02/2019.

KASSOUF, Ana Lúcia. O que conhecemos sobre o trabalho infantil? Nova Economia. Belo Horizonte, v. 17, n. 2, p. 323-350, mai/ago, 2017.

KASSOUF, Ana Lúcia. O trabalho de crianças e adolescentes no Nordeste do Brasil. Brasília, OIT, 2004.

LAZZARATO, Maurizio e NEGRI, Antonio. Trabalho imaterial: formas de vida e produção de subjetividade. Rio de janeio: DP\&A, 2001.

LIBERATI, Wilson Donizete. Adolescente e ato infracional. Medida socioeducativa é pena? São Paulo: Juarez de Oliveira, 2003.

MARQUES, Rafael Dias. Trabalho infantil artístico: possibilidades e limites. Rev. TST, Brasília, v.79, n. 1, p. 204-226, jan./mar. 2013.

MENDRAS, Henri. Sociedades camponesas. Rio de Janeiro: Zahar Editores, 1978.

MYRDAL, Gunnar. Teoria econômica e regiões subdesenvolvidas. Rio de Janeiro: Saga, 1965.

OIT- Organização Internacional do Trabalho. Convenções. Brasília, 2019. Disponível em:

http://www.ilo.org/brasilia/convencoes/WCMS 242947/lang-pt/index.htm. Acesso em: 05 fev. 2019.

OIT- Organização Internacional do Trabalho. Menos pobreza, mais desenvolvimento: como o trabalho decente pode transformar a produção de algodão. Brasília, 2017. Disponível em: http://www.ilo.org/brasilia/noticias/WCMS 578784/lang-pt/index.htm. Acesso em: 14 dez. 2018.

OLIVEIRA, Nilton Marques; STRASSBURG, Udo. Revisitando o pensamento do gunnar myrdal e amartya sen sobre o estado de bemestar social. Revista Ciências Sociais em Perspectiva, v. 15, n. 29, p. 153-169, 2016.

PASTOUREAU, Michel. Os emblemas da juventude: atributos e representações dos jovens na idade medieval. In: GIOVANNI, Levi (Org). História dos Jovens. São Paulo: Cia das Letras, 1996.

PAUL, Camila Izis Avila Barbosa. Trabalho Infantil. Revista LTr Legislação do Trabalho. vol 81, nº 8, p. 122-142, ago de 2017. 
Políticas Públicas De Erradicação Do Trabalho Infantil: Uma Reflexão Apoiada No Projeto...

QUEIROZ, Maria Isaura Pereira de. O campesinato brasileiro: ensaios sobre civilização e grupos rústicos no Brasil. Petrópolis:

Vozes, 1973.

RAMOS, Graciliano. Vidas secas. São Paulo: Record, 1998.

REDFIELD, Robert. O mundo primitivo e suas

transformações. São Paulo: Editora Sociologia e Política, 1956.

RODRIGUES, Joel. Trabalho infantil no campo: cultura ou necessidade? Observa SC, Santa Catarina, o8 jun. 2016. Disponível em: <https://agro.observasc.net/trabalho-infantil-no-campocultura-ou-necessidade/ $>$. Acesso em: 24 nov. 2019.

SARAIVA, João Batista Costa. Direito Penal Juvenil: adolescente e ato infracional: garantias processuais e medidas socioeducativas. Porto Alegre: Livraria do Advogado, 2002.

SCHINDLER, Nobert. Os tutores da desordem: rituais de cultura juvenil nos primórdios da Era Moderna. In: LEVI, Giovanni (org.). História dos jovens. São Paulo: Companhia das Letras, 1996.

SEN, Amartya. 2000. Desenvolvimento como liberdade. São Paulo: Companhia das Letras, 2000.

SOUSA, Clemente Gomes, MATA, Henrique Tome da Costa, BALANCO, Paulo A. de Freitas. Instituições, políticas públicas e financiamento do desenvolvimento regional no Nordeste do Brasil. Disponível em: http://www.eeb.sei.ba.gov.br/pdf/2012/fd/instituicoes politicas pu blicas.pdf. Acesso em: 14 dez. 2018.

VERONESE, Josiane Rose Petry. A proteção integral da criança e do adolescente no direito brasileiro. Revista do Tribunal Superior do Trabalho. Rio de Janeiro: Imprensa Nacional, vol 79, $\mathrm{n}^{\mathrm{O}} \mathbf{1}$, jan/mar, p. 38-54, 2013.

WEBER, Max. Economia e sociedade. Brasília: Editora da Universidade de Brasília, 1991. 


\title{
Child Labour Eradication Taken By Public Action: Decent Work Project As Reflection Basis
}

\author{
Ticyanne Pereira da Silva
}

\section{Gerardo Clésio Maia Arruda}

\begin{abstract}
The Cooperation Cotton project with Decent Work has as goal contribute towards child labour eradication, a phenomenon that is associated with extreme poverty, social inequality and lack of education. Geared by International Labour Office (ILO), the project is executed in partnership with Brazilian Cooperation Agency (ABC) and with Brazilian Cotton Institute (IBA). Although projects success, child labour statistics in Brazil, still, are elevated, being in the Northeast presented the highest incidence. It is aimed in this article, early insertion on labour market causes analysis, in order to contribute directly on state actions, fortify towards child labour counter-action. The methodology is settled on cultural- historic methodology and bibliographic research its privileged. It is concluded state actions Decent Work cooperation project, likewise, must be public agents promoted, once reached development isn't just by capital investment but local particularities analysis too, with dialogue promotion between active parties involved and human capital investment.
\end{abstract}

Keywords: Public Politics. Development. Child Labour.

DOI: https://doi.org/10.22478/ufpb.1678-2593.2020v19n40.45035 